Table 1. Relative Risk of Incident Gout According to Quintiles of DASH and Western Dietary Pattern Scores

\begin{tabular}{|c|c|c|c|c|c|c|}
\hline \multirow[t]{2}{*}{ Variable } & \multicolumn{5}{|c|}{ Frequency of Intake (serving/d) } & \multirow{2}{*}{$\begin{array}{l}\text { P for } \\
\text { trend }\end{array}$} \\
\hline & Q1 & Q2 & Q3 & Q4 & 05 & \\
\hline \multicolumn{7}{|l|}{ DASH Diet } \\
\hline Cases/PY & $396 / 192891$ & $391 / 195970$ & $366 / 196511$ & $332 / 192697$ & $246 / 193455$ & \\
\hline $\begin{array}{l}\text { Age-adjusted RR } \\
(95 \% \mathrm{Cl})\end{array}$ & 1.0 & $0.96(0.83,1.10)$ & $0.88(0.77,1.02)$ & $0.81(0.70,0.94)$ & $51,0.70)$ & $<0.001$ \\
\hline $\begin{array}{l}\text { Multivariable RR } \\
(95 \% \mathrm{Cl})\end{array}$ & 10 & $0.90(0.79,1.04)$ & $0.87(0.76,1.01)$ & $0.82(0.70,0.95)$ & $0.68(0.57,0.80)$ & $<0.001$ \\
\hline \multicolumn{7}{|l|}{ Western Diet } \\
\hline Cases/PY & $287 / 190572$ & $347 / 194533$ & $365 / 196671$ & $346 / 197114$ & $386 / 193182$ & \\
\hline $\begin{array}{l}\text { Age-adjusted RR } \\
(95 \% \mathrm{Cl})\end{array}$ & 1.0 & $1.19(1.02,1.39)$ & $1.25(1.07,1.46)$ & $1.18(1.01,1.38)$ & $1.35(1.16,1.57)$ & $<0.001$ \\
\hline $\begin{array}{l}\text { Multivariable RR } \\
(95 \% \mathrm{Cl})\end{array}$ & 10 & $1.09(0.93,1.28)$ & $1.15(0.98,1.36)$ & $1.12(0.94,1.33)$ & $1.42(1.16,1.74)$ & 0.005 \\
\hline
\end{tabular}

Abbreviations: RR, relative risk: Cl, confidence interval: PY, person-years.

Age-adjusted models adjusted for age and total energy intake.

Conclusions: The DASH dietary pattern is associated with a lower risk of gout, suggesting that its urate-lowering effect among hyperuricemic individuals translates to a lower risk of gout. Conversely, the Western dietary pattern is associated with a higher risk of gout. The DASH diet may provide an attractive preventive dietary approach for the risk of gout, particularly given the high level of cardiovascular comorbidities among this patient population.

References:

[1] N Engl J Med. 1997;336(16):1117-24

[2] N Engl J Med. 2010;362(22):2102-12.

[3] Arthritis Rheumatol. 2016;68(12):3002-3009.

[4] Am J Med. 2012;125(7):679-687.

Acknowledgements: This research was supported by NIH grant R01AR065944. Disclosure of Interest: None declared

DOI: 10.1136/annrheumdis-2017-eular.3925

\section{THU0406 SERUM URIC ACID LOWERING TREATMENT APPEARS UNNECESSARY DURING HEMODIALYSIS}

M. Andrés ${ }^{1,2}$, R. Soriano ${ }^{1}$, E. Oliveira ${ }^{3}$, C. Trigo $^{3}$, M.D. Arenas ${ }^{4}$, E. Pascual ${ }^{2,5}$ ${ }^{1}$ Departamento de Medicina Clínica, Universidad Miguel Hernández; ${ }^{2}$ Seccion de Reumatologia: ${ }^{3}$ Servicio de Análisis Clínicos, Hospital General Universitario de Alicante; ${ }^{4}$ Unidad de Nefrología, Hospital Vithas Perpetuo Socorro; ${ }^{5}$ Emeritus Professor, Universidad Miguel Hernández, Alicante, Spain

Background: Gout patients often suffer from renal disease, some ultimately developing end-stage renal disease (ESRD) and requiring hemodialysis (HD) replacement therapy. Though some reports suggested that tophi disappear after $\mathrm{HD}$, urate-lowering agents are frequently continued, often based on persistent high SUA levels before HD. Also, the impact of SUA levels in the survival of patients on hemodialysis (HD) is under discussion.

Objectives: To assess the SUA reduction achieved under HD and analyze the kinetics of SUA in a week of intermittent HD.

Methods: SUA levels were determined before and after HD sessions in consecutives 96 patients with end-stage renal disease (ESRD), and compared through paired samples Student's t test. Variables related to HD were analyzed whether associated with SUA reductions $\geq 80 \%$ using Student's t test or ANOVA. Also, a kinetics study on selected 10 patients with hyperuricemia (SUA before $\mathrm{HD}>6.8 \mathrm{mg} / \mathrm{dL}$ ) throughout intermittent $\mathrm{HD}$ sessions in a week period was performed; differences in SUA levels were analyzed by repeated measures ANOVA.

Results: Patients were mean aged 66.5 years (SD \pm 13.8$), 62$ males $(64.6 \%)$. Mean time on HD replacement was 7.1 years $( \pm 7.2)$. Before starting HD, $43.0 \%$ had hyperuricemia and $21.6 \%$ reported gout. Sixteen $(16.4 \%)$ continued on uratelowering agents after HD. Mean SUA levels before and after HD session was $5.2 \mathrm{mg} / \mathrm{dL}( \pm 1.0)$ and $1.0 \mathrm{mg} / \mathrm{dL}( \pm 0.4)$, respectively. Mean SUA reduction following HD was $80.2 \%(95 \% \mathrm{Cl} 78.4-82.0) ; 51$ patients $(56.7 \%)$ showed SUA reduction $\geq 80 \%$. HD-related variables $\mathrm{Kt} / \mathrm{v}<1.3 \quad(\mathrm{p}=0.006)$ and blood efflux $<400 \mathrm{~mL} / \mathrm{min}$ $(p=0.004)$ significantly associated with achieving SUA reduction $\geq 80 \%$. Figure shows the SUA kinetics study: SUA significantly reduced all over the period and persisted below hyperuricemia threshold $(p=0.015)$.

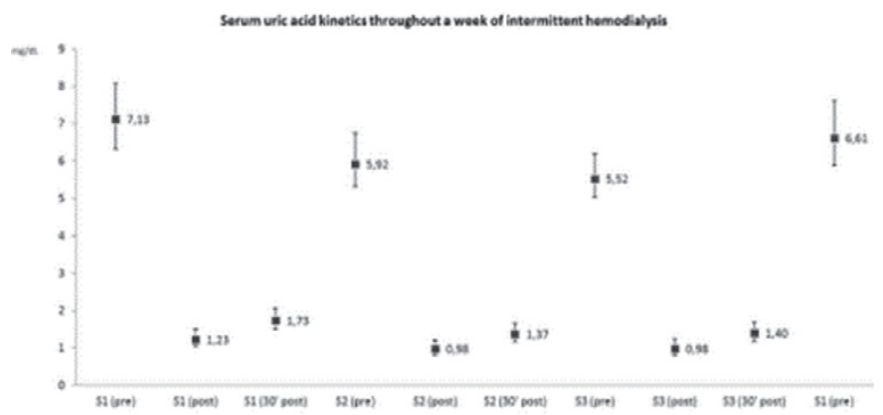

Conclusions: Under HD replacement therapy SUA levels effectively reduced and persisted below saturation point, suggesting that urate-lowering therapy appears unnecessary for patients with gout and ESRD.

Disclosure of Interest: None declared

DOI: 10.1136/annrheumdis-2017-eular.2392

\section{THU0407 HIGH GOUT CLASSIFICATION SCORE IS ASSOCIATED WITH ULTRASOUND FINDINGS IN PATIENTS WITH CRYSTAL-PROVEN GOUT}

T. Uhlig, L.F. Karoliussen, E.A. Haavardsholm, T.K. Kvien, H.B. Hammer.

Rheumatology, Diakonhjemmet Hospital, Oslo, Norway

Background: The recent ACR/EULAR classification (1) classify gout in patients with at least 8 out of maximum 23 points, but presence of monosodium urate crystals in a symptomatic joint/tophus alone is sufficient for gout classification without need for further scoring. It is not known how in crystal-proven patients with increased serum urate (SUA) the whole range of classification points distribute. Objectives: To determine the distribution along the spectrum of ACR/EULAR criteria in crystal-proven patients with insufficiently treated SUA levels, and if disease factors in gout are associated with high classification scores.

Methods: Baseline data from a prospective observational study were used from patients with crystal-proven gout who presented after a recent gout flare. Included patients had at baseline insufficiently treated sUA level (>360 $\mu \mathrm{mol} / \mathrm{L}[>6 \mathrm{mg} / \mathrm{dl}]$ ). Demographic, clinical data and SUA levels were collected from September 2015 to December 2016 in one rheumatology department. Ultrasound of joints was assessed with one total score for double contour sign, tophus, and aggregates in several joints and tendons/entheses. The score for ACR/EULAR criteria for gout was calculated.

Results: 89 patients were included, with baseline mean (SD) age 56.0 (14.8) years, $92 \%$ males, $88 \%$ Caucasians, disease duration 7.9 (7.3) years, presence of palpable tophi $19 \%$, ultrasound score 19.9 (13.8), serum urate $486(90) \mu \mathrm{mol} / \mathrm{L}$, creatinine 78 (18) $\mathrm{ml} / \mathrm{min}$, creatinine clearance 78 (18) $\mathrm{ml} / \mathrm{min}$, ESR 14 (14) $\mathrm{mm} / \mathrm{h}$, body mass index $29.4(4.9) \mathrm{kg} / \mathrm{m}^{2}$, comorbidity score [SCQ] 3.5 (3.2), and physical function [HAQ] $0.34(0.51)$. All patients satisfied clearly the scoring arm of the classification criteria with a median (range) $19(11-23)$ of 23 possible points (Figure 1). Patients with a median and higher score above the median $(\geq 19$ points) vs. lower score reported more gout flares during the last 12 months $(p<0.001)$, had longer disease duration (9.2 vs. $6.2 \mathrm{yrs}, p=0.05)$, and a higher ultrasound score $(23.9$ vs. $14.9, p=0.001)$. The groups with high and low scores were similar for age, gender, ethnicity, level of education, BMI, physical function, comorbidity score, sUA level and kidney function.

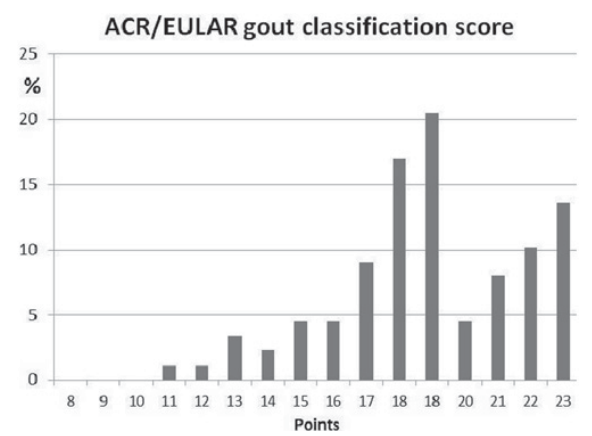

Conclusions: As expected, patients seen in the clinic with crystal-proven gout and at least slightly increased sUA also satisfy the scoring arm of the new classification criteria for gout, supporting their clinical use. Patients with classification points above the median had more flares in the preceding year, and a higher urate burden assessed by ultrasound, but did not have other indicators for a more severe disease.

References:

[1] Neogi T et al. Ann Rheum Dis 2015;74:1789-98.

Disclosure of Interest: T. Uhlig: None declared, L. F. Karoliussen: None declared, E. A. Haavardsholm: None declared, T. K. Kvien Consultant for: Fees for speaking and/or consulting from AbbVie, Biogen, BMS, Boehringer Ingelheim, Celltrion, Eli Lilly, Epirus, Janssen, Merck-Serono, MSD, Mundipharma, Novartis, Oktal, Orion Pharma, Hospira/Pfizer, Roche, Sandoz and UCB, H. B. Hammer: None declared DOI: 10.1136/annrheumdis-2017-eular.2196

\section{THU0408 GOUT IS AN IMPORTANT PREDICTOR OF WORK DISABILITY IN BOTH MEN AND WOMEN}

V. Sigurdardottir ${ }^{1,2}$, P. Drivelegka ${ }^{1}$, A. Svärd ${ }^{2}$, L.T. Jacobsson ${ }^{1}$, M. Dehlin ${ }^{1}$ ${ }^{1}$ Department of Rheumatology and Inflammation Research, Sahlgrenska Academy, University of Gothenburg, Gothenburg: ${ }^{2}$ Centre for Clinical Research Dalarna, Falun, Sweden

Background: Gout is the most common form of inflammatory arthritis with a prevalence of $1.5 \%$ in our area in the age group 50-59 years (1). Gout has a 